\title{
Pengawasan dan Evaluasi Program Bahasa Arab Untuk Peningkatan Berkelanjutan di Universitas Islam Negeri (UIN) Maulana Malik Ibrahim, Malang
}

\author{
Yusuf Mustofa, Thia Razimona*, Dzatu Ulum Nafi'ah, Zakiyah Arifa \\ Universitas Islam Negeri (UIN) Maulana Malik Ibrahim, Malang, Indonesia
}
Supervision and Evaluation of Arabic Language Programs for Improvement Sustainability at State Islamic University (UIN) Maulana Malik Ibrahim, Malang

\section{E-Mail Address \\ thiarazimona05@yahoo.com}

${ }^{*}$ Corresponding Author

\section{Abstract}

This research to find out and explain how controlling and evaluation management occur in the Intensive Program for Arabic Language at the State Islamic University (UIN) Maulana Malik Ibrahim Malang. The background of this research is due to PKPBA is the only language center that organizes Arabic language learning for all new students from all majors, which indeed requires special handling. This research uses descriptive qualitative research, and uses interview techniques, observation, and documentation in collecting data. The results showed that the controlling of a special Arabic language development program at UIN Maulana Malik Ibrahim was an internal controlling carried out by the head of program management, also included in external controlling carried out by the ministry of religion, including active controlling by looking at the program directly, and passive controlling by viewing teacher and student attendance lists, teaching journals, and other learning tools. As well as preventive and repressive controlling carried out to plan and implement the program so that it runs effectively and efficiently and controlling is also carried out after the learning activities are carried out to find out the results of the implementation of the program for further evaluation if there are deviations. While the program evaluation is conducted twice a year, this controlling and evaluation is carried out for continuous improvement which will be carried out every year for the development of the program.

\section{Pendahuluan}

Pengawasan merupakan salah satu fungsi dalam manajemen. Pengawasan juga merupakan kegiatan untuk mengamati dan mengevaluasi pelaksanaan. Selain itu, pengawasan program sangat penting, karena tanpa pengawasan tujuan akan sulit tercapai. Dengan adanya pengawasan pelaksanaan program pun akan semakin terarah. Hal ini menunjukkan bahwa suatu rencana yang baik tidak akan terlaksana dengan baik tanpa pengawasan. Menurut Sarwoto (2010), keberhasilan suatu program 
pembelajaran tidak hanya dinilai dari segi hasil belajar peserta didik, tetapi juga dilihat dari sisi lain, yakni dari keberhasilan proses kegiatan yang telah dilaksanakan dan sesuai dengan rencana awal yang telah ditetapkan. Dalam hal ini fungsi pengawasan dan evaluasi program sangat berperan penting dalam menunjang keberhasilan pelaksanaan program sebagai penentuan apa yang sudah tercapai.

Pengawasan memiliki tujuan untuk mengontrol keberhasilan tujuan agar sesuai dengan tujuan yang telah direncanakan. Artinya, dengan melakukan pengawasan diharapkan dapat mencapai tujuan yang ditetapkan sehingga konsumen menjadi puas. Tindakan pengawasan dibutuhkan untuk memastikan dan mengevaluasi apa yang sudah dilaksakan, apa yang menghambat, dan apakah metode yang digunakan sudah efektif.

Adapun tahap evaluasi merupakan bagian yang tak terpisahkan dari suatu upaya apa pun yang terprogram. Sebuah program yang dilaksanakan di suatu lembaga pasti memiliki sebuah rencana dan tujuan dalam program yang dibuat. Untuk mengetahui apakah perencanaan tersebut terlaksana dengan baik dan sesuai tujuan, maka perlu adanya pengawasan dan evaluasi. Dengan adanya pengawasan dan evaluasi tentunya dapat diketahui apa yang belum terealisasi. Oleh karena itu, penelitian ini akan mengkaji pengawasan dan evaluasi Program Khusus Pembelajaran Bahasa Arab (PKPBA) di Universitas Islam Negeri (UIN) Maulana Malik Ibrahim, Malang. PKPBA UIN Maulana Malik Ibrahim, Malang, merupakan sebuah organisasi program pembelajaran bahasa Arab yang dinaungi oleh Pusat Pengembangan Bahasa (PPB). PKPBA ini diselenggarakan untuk semua mahasiswa baru dari semua fakultas. Tentunya, ini merupakan penelitian yang bagus untuk melihat peserta yang sangat banyak, dan apakah perencanaan program tersebut akan terlaksana dengan baik. Berdasarkan latar belakang tersebut, penelitian ini bertujuan untuk mengetahui bagaimana perencanaan dan pelaksanaan Program Khusus Pengembangan Bahasa Arab (PPKBA), dan untuk menjawab bagaimana pengawasan dan evaluasinya.

\section{Metode Penelitian}

Penelitian ini termasuk jenis penelitian kualitatif deskriptif. Metode penelitian kualitatif dalam mengumpulkan data melalui teknik wawancara, observasi dan dokumentasi. Untuk mendapatkan data tersebut peneliti melakukan wawancara langsung dengan ketua program sekaligus dosen pengampu bidang bahasa Arab di Kantor Pusat Pengembangan Bahasa (PPB) UIN Maulana Malik Ibrahim, Malang. Setelah mendapatkan data utama dari pengawas, peneliti melakukan observasi langsung ketika program berlangsung di kelas untuk mendapatkan kesesuaian data. Adapun dokumentasi digunakan untuk mendapatkan informasi mengenai sistem organisasi serta materi pendukung tentang proses pelaksanaan program.

Peneliti memfokuskan objek penelitian terhadap pengelola sekaligus pengawas program, serta sumber daya manusia sebagai pendukung pelaksanaannya. Dalam melakukan wawancara, peneliti menggunakan wawancara tidak terstruktur atau terbuka karena peneliti ingin mendapatkan informasi mendalam mengenai manajemen program di PKPBA. Observasi dilakukan dengan memantau aktivitas yang sedang berlangsung untuk dikaitkan dengan hasil wawancara. Data pelengkap lain dari peneliti juga termasuk dokumentasi sebagai penguat data. Setelah data penelitian terkumpul, penulis menggunakan teknik analisis data triangulasi. Triangulasi dalam penelitan ini penulis lakukan untuk pengecekan data dari berbagai teknik pengumpulan data terhadap data yang telah diperoleh untuk menguji kredibilitas data tersebut (Sugiono, 2016, pp. 273-274). 


\section{Landasan Teori}

\section{A. Pengawasan}

Menurut Sondang P. Siagian, pengawasan adalah kegiatan pengamatan terhadap organisasi untuk menjamin tugas yang sedang dilaksanakan berjalan sesuai dengan rencana yang telah ditentukan. Pengawasan menurut Sujamto adalah segala usaha untuk mengetahui dan menilai kenyataan yang sebenarnya mengenai pelaksanaan tugas atau kegiatan dengan apa yang semestinya dilakukan (Setiawan, 2018) Pendapat lainnya, Mudrick, menjelaskan bahwa pengawasan merupakan suatu kegiatan pengamatan yang sistematis dimulai dari tahap menentukan standar yang akan dicapai, mengukur pelaksanaan, serta menentukan kesenjangan antara pelaksanaan dan standarnya, sehingga pelaksanaan dapat berjalan sesuai dengan rencana yang telah ditetapkan dan direncanakan (Murdick, 2017, p. 103). Sesuai dengan perannya dalam sebuah organisasi, pengawasan memiliki beberapa fungsi.Fungsi pengawasan antara lain untuk mencegah penyimpangan-penyimpangan, memperbaiki kesalahan atau kelemahan, dan menindak penyalahgunaan serta penyelewengan, mendinamisasi organisasi dan seluruh kegiatan manajemen (Bako et al, 2018, p. 67-69).

Kewenangan proses pengawasan berada pada tanggung jawab pimpinan. Jika pimpinan tidak memungkinkan, maka pimpinan melimpahkan kepada ketua koordinator. Selain itu, pengawasan harus bisa mengukur apa yang telah dicapai dengan apa yang semestinya terjadi atau yang telah direncanakan, menilai pelaksanaan, serta mengadakan tindakan lanjutan yang dipandang perlu. Selain itu, pengawasan harus bisa mengevaluasi diri tentang apa yang telah dicapainya (introspeksi diri). Dengan demikian, dapat ditarik kesimpulan bahwa pengawasan merupakan rangkaian kegiatan untuk meyakinkan bahwa tugas dan pekerjaan telah dilakukan sesuai dengan rencana yang telah ditetapkan serta mengambil tindakan koreksi agar mendapatkan perkembangan hasil pada program selanjutnya.

Pengawasan merupakan bagian dari fungsi manajemen, disamping fungsi perencanaan, pengorganisasian dan pelaksanaan. Jenis-jenis pengawasan sebagai berikut (Setiawan, 2018).

\section{Pengawasan intern dan ekstern}

Pengawasan intern adalah pengawasan yang dilakukan oleh orang dari badan, unit atau pun instansi di dalam lingkungan unit tersebut. Cara pengawasannya dilakukan oleh atasan langsung atau disebut dengan pengawasan melekat (built in control). Sementara itu, pengawasan ekstern berarti pengawasan yang dilakukan di luar dari badan, unit atau instansi tersebut. UUD 1945 pasal 23E: "Untuk memeriksa pengelolaan dan tanggung jawab tentang keuangan negara diadakan suatu Badan Pemeriksa Keuangan yg bebas dan mandiri.

\section{Pengawasan preventif dan represif}

Pengawasan preventif dilakukan sebelum kegiatan dilaksanakan guna mencegah terjadinya kesalahan dan penyimpangan program. Sementara itu, pengawasan represif dilakukan setelah kegiatan dilaksanakan. 


\section{Pengawasan aktif dan pasif}

Pengawasan aktif merupakan pengawasan yang diselenggarakan di tempat dan pada waktu kegiatan berlangsung. Adapun pengawasan pasif dilakukan tidak secara langsung pada kegiatannya, namun melalui dokumen yang meliputi: daftar hadir guru dan siswa, jurnal mengajar, serta perangkat pembelajaran lainnya (Mutakallim, 2016, pp. 355-356).

4. Pengawasan kebenaran formil menurut hak (rechtmatigheid) dan pengawasan kebenaran materil (doelmatigheid) menurut tujuan

Pemeriksaan terhadap pengeluaran atau hasil (output) apakah telah sesuai dengan peraturan dan hak termasuk pengawasan kebenaran formil. Sementara itu, pengawasan kebenaran materil adalah pemeriksaan terhadap pengeluaran, apakah telah memenuhi prinsip ekonomi, yaitu efisiensi penggunaan biaya dan transparansi dalam pengelolaannya atau tepat sasaran. Sasaran pengawasan ditujukan kepada sumber daya manusia yang terlibat dalam pelaksanaan tugas yang berorientasi pada standar dan cara kerja yang baik sehingga hasil (output) yang dicapai mampu memberikan hasil yang baik secara kualitas dan kuantitas.

\section{B. Evaluasi}

Pengawasan tidak bisa dipisahkan dengan kegiatan evaluasi yang menjadikan keduanya seperti mata uang yang benilai dari dua sisi yang berbeda. Pada dasarnya pengawasan mengacu kepada tindakan perbaikan. Hal ini selaras dengan konsep dan pengertian evaluasi menurut para ahli. Gerald W. Wandt Edwint \& Brown (2017) mengemukakan bahwa istilah evaluasi menunjukan pada satu pengertian, yaitu suatu tindakan atau proses untuk menentukan nilai dari sesuatu. Suharsimi Arikunto (2012) mengartikan evaluasi sebagai kegiatan mencari sesuatu yang berharga, juga termasuk mencari informasi yang bermanfaat dalam menilai keberadaan suatu program, produksi, prosedur serta alternatif strategi yang diajukan untuk mencapai tujuan yang telah ditentukan yaitu keberhasilan program. Sementara itu, Nanang Fattah (2017) menjelaskan bahwa evaluasi adalah pembuatan pertimbangan sesuai dengan kriteria yang disepakati dan dapat dipertanggungjawabkan.

Evaluasi program diartikan sebagai proses yang sistematis dan berkelanjutan untuk mengumpulkan, mendeskripsikan, menginterpretasikan, dan menyajikan informasi tentang rancangan program yang telah disusun untuk dapat digunakan sebagai dasar membuat keputusan, menyusun kebijakan maupun menyusun program selanjutnya. Pembahasan evaluasi di sini lebih fokus pada evaluasi program karena dikaitkan dengan manajemen pimpinan atau manajer.

Evaluasi yang digunakan dalam menilai keterlaksanaan suatu program menurut Nanang Fattah (2017) ada dua jenis, yaitu evaluasi internal dan evaluasi eksternal. Evaluasi internal merupakan pengaplikasian standar nilai program yang tertera didalam program itu sendiri. Sementara itu, evaluasi eksternal merupakan penerapan standar nilai dari luar kerangka program.

Kriteria evaluasi internal, antara lain, (1) konsistensi dan kesesuaian antar unsur, seperti tujuan dengan kegiatan, tujuan dengan evaluasi, serta kegiatan dengan evaluasi; (2) Penyebaran sumber. Sumber daya manusia memiliki kriteria yang spesifik untuk kesuksesan program. Dalam struktur pengajaran, misalnya, juga harus berorientasi pada kemampuan dan profesionalitas. Sumber daya biaya juga harus berorientasi pada efisiensi dan transparansi; dan (3) kemampuan generatif program, 
yaitu kemampuan dalam membuahkan hasil-hasil positif secara alamiah, ide-ide positif dari program dapat bermanfaat untuk mengembangkan kemampuan lain.

Adapun kriteria evaluasi eksternal antara lain, (1) Pengarahan kebijakan. Programnya antara lain, penataran, lokakarya, workshop, seminar, dan lain sebagainya. Tujuannya untuk mengarahkan kebijakan kepada kualitas program; 2) Analisis keuntungan dan biaya. Menganalisis keuntungan dengan biaya program berarti membandingkan antara biaya dengan keuntungan yang dihasilkan. Jika program yang dilaksanakan nonprofit, berarti dengan menganalisis dampak terhadap hasil; dan 3) Efek Lipat Ganda. Menilai efek lipat ganda bermakna menilai dampak lain jika ikut terpengaruhi dari dampak suatu program di luar dampak sasaran. Misalnya, dalam program pendidikan, selain tujuan dampak sasarannya terhadap peserta didik, orang tua dan lingkungan juga mendapatkan dampak dari adanya program tersebut.

\section{Hasil Penelitian}

Penelitian ini dilaksanakan di UIN Maulana Malik Ibrahim, Malang dengan tujuan untuk mendapatkan informasi tentang manajemen Program Khusus Pembelajaran Bahasa Arab (PKPBA). Berdasarkan hasil wawancara terbuka, peneliti dapat mendeskripsikannya secara tertulis pada penelitian ini. PKPBA merupakan sebuah organisasi program pembelajaran bahasa Arab yang dinaungi oleh Pusat Pengembangan Bahasa (PPB) UIN Maulana Malik Ibrahim, Malang. PKPBA sendiri berdiri sejak tahun 1997 sebagai program pembelajaran di luar jam perkuliahan yang diperuntukkan bagi mahasiswa baru.

Menurut ketua PKPBA bapak DH, penyelenggaraan program khusus pembelajaran bahasa Arab dikelola oleh pengurus PKPBA bersama team teaching. Program ini termasuk program di luar kegiatan formal universitas. Dalam satu tahun pertama menjabat sebagai ketua PKPBA, Beliau memiliki tujuan dalam mengatur program pembelajaran bahasa Arab agar berjalan dengan baik. Tujuan program pembelajaran bahasa Arab di UIN Maulana Malik Ibrahim, Malang, ini untuk membekali mahasiswa untuk mengenal bahasa Arab, suka dengan bahasa Arab, dan mampu berbahasa Arab komunikatif. Pada tahun sebelumnya, pelaksanaan program pembelajaran belum berjalan secara efektif karena kurangnya perencanaan dosen untuk mengajar sehingga terkadang pelaksanaan pembelajaran tidak berjalan efektif. Bahkan, banyak dosen yang kurang disiplin dan absen.

Informasi di atas menunjukkan ketetepatan peneliti dalam mengambil subjek penelitian, karena beliau sangat paham tentang pentingnya fungsi manajemen keempat ini. Oleh karena itu, peneliti dapat mengakses informasi yang jelas tentang pengawasan dan evaluasi Program Khusus Pembelajaran Bahasa Arab (PKPBA). Sebelum peneliti menjelaskan bagaimana proses pengawasan dan evaluasi tersebut, perlu peneliti paparkan terlebih dahulu rencana dan pelaksanaan yang telah disusun oleh ketua Program Khusus Pembelajaran Bahasa Arab (PKPBA) untuk memudahkan peneliti dalam memaparkan pengawasan dan evaluasinya.

\section{A. Perencanaan dan Pelaksanaan PKPBA}

Perencanaan Program Khusus Pembelajaran Bahasa Arab (PKPBA) di UIN Maulana Malik Ibrahim, Malang, adalah sebagai berikut: 
1. Menentukan kualifikasi pengajar.

2. Melakukan placement test awal untuk mengetahui kemampuan mahasiswa.

3. Mengklasifikasi peserta didik berdasarkan hasil test yang terdiri dari 3 kelompok (mubtadi, mutawassit, dan mutaqaddim) di setiap fakultas. Saat ini program pembelajaran bahasa Arab di UIN Maulana Malik Ibrahim, Malang, terdiri dari 92 kelas dengan rincian sebagai berikut.

Tabel 1. Perincian kelas PKPBA di UIN Maulana Malik Ibrahim, Malang

\begin{tabular}{clc}
\hline No & \multicolumn{1}{c}{ Fakultas } & Jumlah Kelas \\
\hline 1. & Ilmu Tarbiyah dan Keguruan & 21 \\
2. & Syariah & 14 \\
3. & Humaniora & 12 \\
4. & Psikologi & 7 \\
5. & Ekonomi & 14 \\
6. & Sains dan Teknologi & 21 \\
7. & Kedokteran & 2 \\
\hline \multicolumn{2}{c}{ Jumlah } \\
\hline
\end{tabular}

4. Membuat jadwal pembelajaran.

5. Menyusun materi pembelajaran ( 4 buku panduan) karya dosen UIN Maulana Malik Ibrahim, Malang, untuk proses pembelajaran selama periode program (1 tahun).

6. Membuat struktur kepengurusan meliputi ketua program, sekretaris merangkap bidang administrasi, koordinator wali kelas dan wali kelas.

Adapun pelaksanaan Program PKPBA meliputi,

1. Menyelenggarakan proses pembelajaran di kelas selama 2 jam pertemuan ( 2 x 90 menit) dalam sehari.

2. Pelaksanaan perkuliahan bahasa arab berlangsung selama 5 hari dalam seminggu.

3. Pelaksanaan program diikuti oleh 152 pengajar dan 3400 peserta didik .

4. Pelaksanaan kelas dibawah tanggung jawab dosen wali, sehingga jam mengajar wali kelas lebih banyak daripada dosen yang bukan wali kelas.

\section{B. Pengawasan dan Evaluasi PKPBA}

Berdasarkan hasil wawancara dengan Ketua Program Kkhusus Pembelajaran Bahasa Arab (PKPBA) bahwa pengawasan program bahasa Arab sudah dilaksanakan melalui pengamatan langsung, dokumentasi, dan evaluasi melalui mahasiswa. Pengawasan program PKPBA dilakukan melalui koordinator wali kelas (ketua team teaching) dengan cara menunjuk koordinator setiap 7 wali kelas untuk memudahkan ketua pengelola program dalam memantau keaktifan setiap wali kelas dan pengajar. Pengawasan juga dilakukan langsung oleh ketua pengelola program dengan memantau pelaksanaan pembelajaran di kelas. Pengawasannya dilakukan tanpa jadwal tertentu atau acak agar pelaksanaan program pengawasan pembelajaran berjalan dengan efektif dan efisien tanpa mengganggu pelaksanaan pembelajaran. Pengawasan juga dilakukan melalui dokumen (perangkat pembelajaran), yakni jurnal harian dosen dan mahasiswa, serta daftar hadir dosen dan mahasiswa.

Evaluasi program maksimal dilakukan 2 kali dalam setahun, yakni pada setiap akhir semester untuk membahas ujian akhir semester peserta didik, sekaligus mengecek sejauhmana materi yang 
belum tercapai. Evaluasi dilakukan dengan mengumpulkan koordinator wali atau mengumpulkan seluruh wali minimal sebulan sekali. Evaluasi terhadap hasil belajar peserta didik berdasarkan materi yang telah disampaikan oleh pengajar.

\section{Pembahasan}

Berdasarkan hasil penelitian, berikut ini akan dijelaskan tentang bentuk pengawasan dan evaluasi program pembelajaran bahasa Arab di Program Khusus Pembelajaran Bahasa Arab (PKPBA) UIN Maulana Malik Ibrahim, Malang.

\section{A. Tujuan/ Perencanaan PKPBA}

Tujuan program pembelajaran bahasa Arab di UIN Maulana Malik Ibrahim, Malang, ini untuk membekali mahasiswa untuk mengenal bahasa Arab, suka dengan bahasa Arab, dan mampu berbahasa Arab komunikatif. Perencanaan program pembelajaran bahasa Arab, yakni dengan menentukan tenaga pengajar yang profesional dalam bidang bahasa Arab, mengklasifikasikan mahasiswa sesuai dengan kemampuan, menyusun jadwal pelaksanaan program pembelajaran bahasa Arab. Selain itu, juga menentukan materi pembelajaran, dan strategi pembelajaran juga diseragamkan. Perencanaan program pembelajaran ini sangat penting sebagai peningkatan mutu pendidikan.

\section{B. Pelaksanaan Program Pembelajaran PKPBA}

Berdasarkan hasil penelitian pelaksaan program pembelajaran bahasa Arab di PKPBA UIN Maulana Malik Ibrahim, Malang, sudah berjalan sesuai dengan tujuan dari program tersebut, yakni untuk membekali mahasiswa untuk mengenal bahasa Arab, suka dengan bahasa Arab, dan mampu berbahasa Arab komunikatif. Untuk mencapai tujuan program tersebut disusun perencanaan program yang sistematis, terutama dalam bidang sumber daya manusia (SDM) yang berperan dalam perencanaan dan pelaksanaan program tersebut.

\section{Pengawasan dan Evaluasi PKPBA}

Kewenangan proses pengawasan berada pada tanggung jawab pimpinan. Jika pimpinan tidak memungkinkan, maka pimpinan melimpahkan kepada ketua koordinator. Pengawasan harus bisa mengukur objek apa yang telah dicapai, menilai pelaksanaan, serta mengadakan tindakan lanjutan yang dipandang perlu. Selain itu, pengawasan harus bisa mengevaluasi diri tentang apa yang telah dicapainya (introspeksi diri).

Berdasarkan hasil wawancara penulis dengan ketua PKPBA UIN Maulana Malik Ibrahim, Malang, pengawasan program bahasa Arab dilaksanakan oleh ketua PKPBA melalui team teaching (koordinator wali), dan terkadang juga melalui pengamatan langsung oleh ketua dengan langsung melihat proses pembelajaran di setiap kelas. Pengawasan ini dilakukan oleh ketua secara acak agar pelaksanaan program pembelajaran berjalan dengan efektif dan efisien. Pengawasan juga dilakukan melalui dokumen, yakni jurnal harian dosen dan mahasiswa. Evaluasi program maksimal dilakukan 2 tahun sekali, yakni pada setiap akhir semester. Selain itu, setiap minggu juga diadakan pertemuan 
antarkoordinator wali dengan ketua untuk membahas tentang pelaksanaan program pembelajaran bahasa Arab PKPBA.

Menurut peneliti, pengawasan yang dilakukan oleh PKPBA merupakan jenis pengawasan intern dan ekstern. Pengawasan langsung dilakukan oleh ketua melalui team teaching, atau pengawasan dilakukan oleh pihak yang berada di unit atau instansi di dalam lingkungan unit tersebut. Pengawasan dilakukan oleh Kepala Pusat Pengembangan Bahasa (PPB) UIN Maulana Malik Ibrahim, Malang, terhadap ketua PKPBA. Hal ini sesuai dengan istilah pengawasan intern itu sendiri yang berarti pengawasan yang dilakukan oleh orang dari badan atau unit ataupun instansi di dalam lingkungan unit tersebut. Cara pengawasannya dilakukan oleh atasan langsung atau disebut dengan pengawasan melekat (built in control). Pengawasan intern program pembelajaran di PKPBA UIN Maulana Malik Ibrahim, Malang, dilakukan oleh Ketua PKPBA dengan cara pengamatan langsung dan melihat proses pembelajaran di setiap kelas. Sementara itu, pengawasan ekstern berarti pengawasan yang dilakukan di luar dari badan atau unit atau instansi tersebut. Pengawasan ekstern program pembelajaran bahasa Arab di PKPBA dilakukan oleh kementerian Agama RI dengan melakukan pengawasan langsung ke PKPBA UIN Maulana Malik Ibrahim, Malang.

Pengawasan preventif dilakukan sebelum kegiatan dilaksanakan guna mencegah terjadinya kesalahan dan penyimpangan program, sedangkan pengawasan represif dilakukan setelah kegiatan dilaksanakan. Pengawasan preventif dan represif yang dilakukan dalam program pembelajaran PKPBA UIN Maulana Malik Ibrahim, Malang, adalah pengawasan yang dilakukan untuk merencanakan dan melaksanakan program agar berjalan secara efektif dan efisien. Pengawasan ini juga dilakukan setelah kegiatan pembelajaran dilaksanakan guna untuk mengetahui hasil pelaksanaan program untuk selanjutnya dilakukan evaluasi jika terdapat penyimpangan.

Pengawasan aktif merupakan pengawasan yang diselenggarakan di tempat dan pada waktu kegiatan berlangsung. Adapun pengawasan pasif dilakukan tidak secara langsung pada kegiatannya, namun melalui dokumen yang meliputi daftar hadir guru dan siswa, jurnal mengajar, serta perangkat pembelajaran lainnya. Pengawasan program di PKPBA termasuk ke dalam jenis pengawasan aktif dan pasif, yakni pengawasan yang dilakukan saat proses pembelajaran berlangsung, dan pengawasan pasif dilakukan melalui daftar hadir dan jurnal mengajar.

Pengawasan di PKPBA juga termasuk kebenaran formil menurut hak, misalnya pengawasan ketua terhadap proses pelaksanaan pembelajaran agar peserta didik berhak mendapatkan pendidikan yang baik dan terstruktur (terjadwal). Sementara itu, pengawasan terhadap kebenaran materi menurut tujuan, yaitu pengawasan ketua dalam pemberian tunjangan pengajar, apakah sudah sesuai tujuan dan tepat sasaran karena sistem penggajiannya sesuai jam mengajar yang dijalankan.

Terakhir, evaluasi program diartikan sebagai proses yang sistematis dan berkelanjutan untuk mengumpulkan, mendeskripsikan, menginterpretasikan, dan menyajikan informasi tentang rancangan program yang telah disusun untuk dapat digunakan sebagai dasar membuat keputusan, menyusun kebijakan, maupun menyusun program selanjutnya. Pembahasan evaluasi di sini lebih fokus pada evaluasi program karena dikaitkan dengan manajemen pimpinan atau manajer. Pengawasan dan evaluasi ini dilakukan untuk peningkatan berkelanjutan yang setiap tahun akan dilaksanakan untuk peningkatan program. 


\section{Simpulan}

Pengawasan dan evaluasi suatu program penting dilakukan agar program berjalan sesuai dengan yang telah direncanakan. Pelaksanaan Program Khusus Pembelajaran Bahasa Arab (PKPBA) di UIN Maulana Malik ibrahim, Malang, sudah terlaksana sesuai dengan yang telah direncanakan. Pengawasan yang ada di program PKPBA dilakukan oleh ketua PKPBA (intern) dan pengawasan yang dilakukan oleh Kementrian Agama RI terhadap PKPBA (ekstern). Pengawasan program PKPBA dilakukan sebelum dan sesudah proses pembelajaran berlangsung. Pengawasan dilakukan secara aktif melalui pengamatan langsung, dan pengawasan pasif dilakukan melalui daftar hadir dan jurnal. Pengawasan di PKPBA juga termasuk kebenaran formil menurut hak, misalnya pengawasan ketua terhadap proses pelaksanaan pembelajaran agar peserta didik berhak mendapatkan pendidikan yang baik. Pengawasan terhadap kebenaran materi menurut tujuan yaitu pengawasan ketua dalam pemberian tunjangan pengajar apakah sudah sesuai tujuan dan tepat sasaran karena sistem penggajiannya sesuai jam mengajar yang dijalankan. Sementara itu, evaluasi program yang dilakukan di PKPBA adalah evaluasi internal dan eksternal. Pengawasan dan evaluasi ini dilakukan untuk peningkatan berkelanjutan yang setiap tahun akan dilaksanakan untuk peningkatan program.

\section{Daftar Rujukan}

Arikunto, S. (2012). Dasar-dasar evaluasi pendidikan (2 ${ }^{\text {th }}$ ed.) Jakarta: Bumi Aksara.

Baharuddin, \& Makin, M. (2010). Manajemen pendidikan Islam: Tranformasi menuju sekolah/madrasab unggul. Malang: UIN Maliki Press.

Bako, F. M., Masruroh, F., Tuli, F., \& Arifah, D. (2018). Pengawasan dan evaluasi program bahasa Arab di pondok pesantren. Arabi: Journal of Arabic Studies, 3(1), 61-69. doi:10.24865/ajas.v3i1.72

Edwin, G. W. W., \& Brown. (1997). Esential of educational evaluation. New York: Holt Rinehart \& Winston.

Fattah, N. (2017). Landasan manajemen pendidikan. Bandung: PT. Remaja Rosdakarya.

Mutakallim. (2016). Pengawasan, evaluasi, dan umpan balik stratejik. Jurnal Inspiratif Pendidikan, 5(2), 351-365. doi:10.24252/ip.v5i2.3489

Murdick, R. G. (2017). Sistem informasi untuk manajemen modern. Jakarta: Erlangga.

Setiawan, S. (2018, January 3). Pengertian pengawasan, makna, jenis, tujuan, manfaat, fungsi, prinsip, tahap, para ahli. Gurmpendidikan.com. Retrieved from https://www.gurupendidikan.co.id/pengertian-pengawasan/

Sugiono. 2016. Metode penelitian kuantitatif, kualitatif, dan RE $\sigma^{\circ}$. Bandung: Alfabeta. 